\title{
The Effect of miR-1468 on Growth Hormone in Pituitary Cells of Yanbian Yellow Cattle
}

\author{
Tai-hua Jin ${ }^{1}$, An-gang Lou ${ }^{2}$ Jiu-xiu $\mathrm{Ji}^{1}$, Cheng-dou $\mathrm{Cui}^{2}$, Long-zheng $\mathrm{Yu}^{2}$ and \\ Li-zeng Guan ${ }^{1 *}$ \\ ${ }^{1}$ College of Agriculture and Forestry Science, Linyi University, Linyi 276005, China \\ ${ }^{2}$ Agriculture College, Yanbian University, Yanji 133000, China
}

Tai-hua Jin and An-gang Lou contributed equally to this work.

\begin{abstract}
A B S T R A C T
At present, the relationship between miRNAs and $G H$ has been reported. However, the effect of miR1468 on growth hormone $(G H)$ is unknown. The objective of this study was to evaluate effects of miR-1468 on $G H$ in pituitary cells of Yanbian yellow cattle in this study. Real-time quantitative PCR (qPCR), Western blot, Targetscan and RNAhybrid analysis software and Dual-Luciferase reporter gene system was used to analyze the regulation mechanism between miR-1468 and $G H$. The results showed that the $G H$ mRNA and protein level in pituitary cells of Yanbian yellow cattle could be significantly decreased by adding miR-1468 mimics $(P<0.01)$, while these were significantly increased by adding miR-1468 inhibitor $(P<0.05)$. The results of bioinformatics analysis and double luciferase reporter gene system validation showed that miR-1468 targeted 3'UTR of cAMP responsive element binding protein 1 (CREB1). miR-1468 mimics could significantly inhibit the CREB1 mRNA and protein level $(P<0.01)$, whereas miR-1468 inhibitor could significantly increase the $C R E B 1 \mathrm{mRNA}$ and protein level $(P<0.01)$. This study demonstrated that miR-1468 could regulate GH in pituitary cells by regulating the expression of $C R E B 1$ gene. The results of this study will provide a theoretical basis for studying the mechanism of growth and development of animals regulated by miRNAs.
\end{abstract}

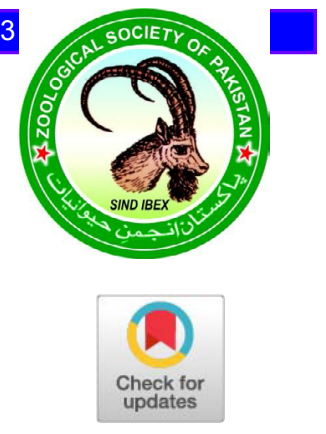

\section{INTRODUCTION}

Y anbian yellow cattle are characterized by slow growth rate, long growth cycle, which lead to the waste of feed resources and increase of feeding costs and and consequently negative effects on the Yanbian yellow cattle breeding industry (Han et al., 2010; Tian et al., 2011; Ji et al., 2014). Therefore, how to improve the growth rate of Yanbian cattle is the key to accelerate the rapid development of Yanbian cattle breeding industry.

Some studies have shown that miRNAs in play an important role in regulating the growth and development of animals. For example, Melnik et al. (2013) found that miRNA-21 in milk could promote calf growth. Chen et al. (2014) used miR-PC-86 and miR-PC-263 derived from pig to treat $\mathrm{C} 2 \mathrm{C} 12$ cells and found that miR-PC-86 and miR-PC-263 could regulate the expression of IGF-1R receptor on $\mathrm{C} 2 \mathrm{C} 12$ cells and further regulate the growth of porcine muscle cells.

The growth axis plays a key role in the growth and development of animals (Vgontzas et al., 2010;

\footnotetext{
* Corresponding author: guanlizeng@163.com 0030-9923/2021/0004-1425 \$ 9.00/0

Copyright 2021 Zoological Society of Pakistan
}

Allen et al., 2011; Bustin and Jenkins, 2001). The growth hormone $(\mathrm{GH})$ secreted by the pituitary gland in the growth axis is one of the most important members in the regulation of animal growth (Piotrowska et al., 2017; King et al., 2005). GH can be transported by binding to growth hormone binding protein (GHBP) and to growth hormone receptor (GHR) in target organs, which promotes the production of insulin-like growth factors (IGFs). IGFs are then transported to whole body tissues and cells by binding to insulin-like growth factor binding protein (IGFBP) to stimulate the growth and differentiation of bone and chondrocyte and regulate the metabolism of protein, sugar and fat, etc. (Gesing, et al., 2016; Bartke et al., 2003). Some studies have shown that there is a relationship between miRNAs and GH gene. Qi et al. (2015) found that mi-1413 p might regulate $G H$ by targeting SOCS7 (suppressor of cytokine signaling) and inhibiting CREB1 (cyclic AMP response element binding protein 1) expression and activity. In our previous study, the miRNAs related to $G H$ regulation in the pituitary of Yanbian yellow cattle were analyzed by RNASEQ sequencing and bioinformatics techniques, and finally miR-1468 was selected out (Lou et al., 2019).

However, the effect of miR-1468 on GH secretion in pituitary of Yanbian yellow cattle is still unclear. 
Therefore, the purpose of this study is to explore the regulation mechanism of miR-1468 on GH secretion in pituitary of Yanbian yellow cattle at the level of pituitary cells in vitro.

\section{MATERIALS AND METHODS}

Primary culture of pituitary cells of Yanbian yellow cattle

The pituitary tissues of three Yanbian yellow cattle were separated under aseptic conditions and cut into 1 $\mathrm{mm} \times 1 \mathrm{~mm}$ tissue mass, respectively and then were washed with PBS for three times at $\mathrm{pH}$ 7.0. The tissue precipitation was transferred to culture flask, and $0.5 \mathrm{~mL} 0.25 \%$ collagenase and trypsin (TaKaRa, Tokyo, Japan) were added to each pituitary tissues and incubated in shaking bed at $37{ }^{\circ} \mathrm{C}$ for $25 \mathrm{~min}$. The pituitary cells were filtered with 100 meshes cell sieve. The filtrate was centrifuged at $4^{\circ} \mathrm{C}, 2000 \mathrm{rpm}$ for $10 \mathrm{~min}$ and the supernatant was discarded. Cells were suspended in DMEM/F12 medium (QIAGEN, Hilden, Germany) and cultured in $75 \mathrm{~mL}$ culture flask at $37{ }^{\circ} \mathrm{C}$ and $5 \% \mathrm{CO}_{2}$ incubator. When the cells grew up to $80 \%$ of convergence, they were digested with $0.25 \%$ collagenase (TaKaRa, Tokyo, Japan). The cells were isolated by differential adherence method and primary cultured pituitary cells were obtained.

\section{Expression level of miR-1468 in pituitary cells}

After the primary culture of Yanbian yellow cattle pituitary cells was established, the pituitary cells were inoculated into 6-well culture plate according to the density of $2.0 \times 10^{6}$ cells/hole, and transfection test was carried out when the cell confluence was $60 \%-70 \%$. The pituitary cells were washed with $2 \mathrm{~mL}$ PBS once before transfection, and $0.8 \mathrm{~mL}$ DMEM/F12 medium was added. Mimics (miR-1468-mi group), mimics reference substance (NC group), inhibitor (miR-1468-in group) and inhibitor reference substance (iNC group) of miR-1468 were diluted to $100 \mu \mathrm{L}$ DMEM/F12 medium respectively. The miR-1468 mimic, inhibitor, NC and inhibitor were purchased from Sangon Biotech Co. (Shanghai, China). The sequences were as follows: miR-1468 mimic (5'-CUCCGUUUGCCUGUUUUGCUGA-3'), miR-1468 inhibitor (5'-UCAGCAAAACAGGCAAACGGAG-3'), NC (5'-UCAAACGCCACCGUAG CAUUC -3'), and iNC (5'-GAGUAACGCCCUAGUUGACCU- ${ }^{\prime}$ ). The 10 $\mu \mathrm{L}$ transfection reagent Lipofectamine ${ }^{\mathrm{TM}} 2000$ (QIAGEN, Hilden, Germany) was diluted to $100 \mu \mathrm{L}$ DMEM/F12 culture medium and then mixed with above diluents in a ratio of $1: 1$, respectively. After incubation at room temperature for $10 \mathrm{~min}, 200 \mu \mathrm{L}$ mixture was added into the cell pore of the preconditioned cells, and the final concentration of mimics, mimics reference substances, inhibitor and inhibitor reference substances of miR-1468 was $200 \mathrm{pmol} / \mathrm{L}$, with three replicates in each group. After culture for $48 \mathrm{~h}$, the cells were collected and the total RNA was extracted. miR-1468 expression level was detected using fluorescence quantitative PCR (qPCR).

Total RNA was extracted from pituitary cells by Trizol reagent and digested with DNase I (TaKaRa, Tokyo, Japan) to remove trace DNA contamination. The cDNA synthesis was catalyzed by M-MLV reverse transcriptase (TaKaRa, Tokyo, Japan) using total RNA as a template and the specific neck loop primer (5'CTCAACTGGTGTCGTGGAGTCGGCAATT AGTTGAGCACAAATT3') (Qi et al., 2015). Primer Premier 6.0 software was used to design the forward and reverse primers for the PCR amplification of miRNA and $U 6$ genes. The forward and reverse primers of miR-1468 were 5'-CCTACCCTGTAGAACCG-3' and 5'-TGGTGTCGTGGAGTCG -3', respectively; The forward and reverse primers of U6 were 5'-CTCGCTTCGGCAGCACA-3' and AACGCTTCACGAATTTGCGT, respectively. PCR mixture contained $5 \mu \mathrm{L}$ of SYBR Green Master Mix (TaKaRa, Tokyo, Japan), $0.5 \mu \mathrm{L}$ of $10 \mathrm{mM}$ each of primers, $1 \mu \mathrm{L}$ of cDNA and $3 \mu \mathrm{L}$ of PCR water. The PCR conditions were as follows: $95^{\circ} \mathrm{C}$ for $5 \mathrm{~min}$, followed by 40 cycles of $95^{\circ} \mathrm{C}$ for $10 \mathrm{~s}, 56^{\circ} \mathrm{C}$ for $20 \mathrm{~s}$ and $72^{\circ} \mathrm{C}$ for 20 $\mathrm{s}$, and the fluorescence signals were then collected. The

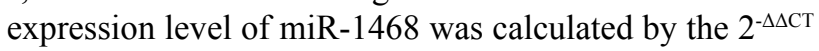
method. The formula is as follows: $\Delta \mathrm{Ct}=\mathrm{miR}-1468 \mathrm{Ct}-U 6$ $\mathrm{Ct} ; \Delta \Delta \mathrm{Ct}=[(\mathrm{miR}-1468 \mathrm{Ct}$-negative control $\mathrm{Ct})-(\mathrm{U} 6 \mathrm{Ct}-$ negative control $\mathrm{Ct}$ )]

Effect of miR-1468 on GH mRNA transcription level in Yanbian yellow cattle pituitary cells

The cDNA synthesize was catalyzed by M-MLV reverse transcriptase (TaKaRa, Tokyo, Japan) using total RNA as template and OligodT-18 as primer. Primer Premier 6.0 software was used to design upstream and downstream primers of $G H$ gene and $\beta$-actin gene in Yanbian yellow cattle. The forward and reverse primers of $\beta$-actin were: CCACGAAACTACCTTCAACTC and CCCACGAAACTACCTTCAACTC, respectively. The forward and reverse primers of $G H$ were: CTCCAACTGCTGGCTGCCGACAGCTA and CGATGTCTGCTGGGCTCGTCC, respectively. The PCR reaction system consisted of $10 \mu \mathrm{L}$ of SYBR Green Master Mix, $0.3 \mu \mathrm{L}$ of $10 \mathrm{mM}$ each of primers, $1 \mu \mathrm{L}$ of cDNA and $8.4 \mu \mathrm{L}$ of sterile water. The PCR reaction procedure was: $95^{\circ} \mathrm{C}$ for $1 \mathrm{~min}$, then 40 cycles of $95^{\circ} \mathrm{C}$ for $15 \mathrm{~s}, 55^{\circ} \mathrm{C}$ for $15 \mathrm{~s}$ and $72^{\circ} \mathrm{C}$ for $40 \mathrm{~s}$, and the fluorescence signals were collected at the end of the extension. The expression level of $G H$ gene was calculated by $2^{-\Delta \Delta C \mathrm{CT}}$ method. The formula was: $\Delta \mathrm{Ct}=G H \mathrm{Ct}-\beta$-actin $\mathrm{Ct} . \Delta \Delta \mathrm{Ct}=[(G H \mathrm{Ct}$-negative control $\mathrm{Ct})-(\beta$-actin $\mathrm{Ct}$-negative control $\mathrm{Ct})]$. 
Effect of miR-1468 on GH protein expression in pituitary cells of Yanbian yellow cattle

According to the steps of the total protein extraction kit (Roche, Basel, Switzerland), the total protein was extracted from the above obtained cells, and the GH protein was detected by Western blot method. The specific steps were as follows: $10 \%$ polyacrylamide gel electrophoresis (PAGE) separating gel and 5\% PAGE concentrating gel were prepared according to the conventional method and put into the vertical electrophoresis tank. After solidification, the wood comb was pulled out and the $1 \times$ glycine buffer was added into the comb hole, then $50 \mathrm{~g}$ prepared total protein sample was added into the comb hole for electrophoresis. After electrophoresis, the protein glue was transferred to polyvinylidene fluoride (PVDF) membrane (Roche, Basel, Switzerland) with a voltage of $110 \mathrm{~V}$ for $60-70$ min. Then the PVDF membrane was taken out and stained with Ponceau red to test the effect of transmembrane. The PVDF membrane was washed for several times with $1 \times$ Tris- $\mathrm{HCl}$ and tween buffer (TBST) solution to remove the Ponceau dye solution, and then sealed for $2 \mathrm{~h}$ at room temperature with 5\% skimmed milk powder. After that, the sealed PVDF membrane was placed in a $5 \mathrm{~mL}$ centrifugal tube and $2 \mathrm{~mL}$ first antibody (rabbit, monoclonal antibody) (Bioss, Beijing, China) of $\mathrm{GH}$ protein was added in to the centrifugal tube and incubated for $12 \mathrm{~h}$ at $4{ }^{\circ} \mathrm{C}$. After incubation, PVDF membrane was washed 3 times with $1 \times$ TBST solution for 10 min each time. The washed PVDF membrane was placed in a new $5 \mathrm{~mL}$ centrifugal tube and incubated at room temperature for $2 \mathrm{~h}$ with $2 \mathrm{~mL} \mathrm{1:5000}$ diluted second antibody (mouse monoclonal antibody) (Bioss, Beijing, China) of GH protein. After incubation, the PVDF membrane was washed 3 times with $1 \times$ TBST for 5 min each time. Then the PVDF membrane was placed in the luminescent liquid for $1 \mathrm{~min}$ and exposed in the gel imaging system. The relative expression of GH protein was calculated by comparing with the expression of $\beta$-actin as a reference gene.

\section{Target gene prediction of miR-1468}

Targetscan and RNA hybridization analysis software were used to predict the target relationship between miR1468 and $G H$ related genes including growth hormone releasing hormone receptor $(G H R H R)$, somatostatin receptor 2 (SSTR2), lymphoid enhancer 1 (LEF1), pituitary specific transcription factor 1 (POU1F1), somatostatin receptor 5 (SSTR5) and cyclic adenosine phosphate effector binding protein 1 (CREB1).

Verification of the target relationship between miRNA-1468 and CREB 1

The upstream and downstream sequence within $30 \mathrm{bp}$ of CREB1 3'UTR region matched with the seed sequence of miR-1468 was synthesized, and the 5 bases of the seed sequence of miR-1468 were mutated artificially as a control. The synthetic fragments and mutant fragments were digested by $X h o \mathrm{I}$ and $X b a \mathrm{I}$ (TaKaRa, Tokyo, Japan). Then the recombinant pirGLO-CREB1-3'UTR expression vector and mutant vector were constructed by linking the digested products with the luciferase gene report vector (pirGLO vector), respectively. Mimic (miR-1468-mi group) and mimics reference substance (NC group) of miR-1468 and the normal or mutant vector of pirGLOCREB1-3'UTR were diluted to $200 \mathrm{pmol} / \mathrm{L}$ respectively, and then co-transfected into Chinese hamster ovary cell (CHO) cells by transfection reagent Lipofectamine ${ }^{\mathrm{TM}}$ 2000. The specific transfection process was as described above. Cells were collected and lysed after incubating for $48 \mathrm{~h}$ and luciferase activity was detected by luciferase detection kit (Promega, Wisconsin, USA).

Effects of miR-1468 on the transcriptional level and protein expression of CREB1 in pituitary cells of Yanbian yellow cattle

The mRNA transcription level and protein expression of $C R E B 1$ were evaluated by the detection methods for $G H$. CREB1 fragment was amplified by forward (ACCCATGCTACTGTCCACTA) and reverse (GAAAGCCCTAGGCTGAATGA) primers, respectively. For Western blot test, the PVDF membrane containing CREB1 protein was incubated with $2 \mathrm{~mL}$ 1:500 diluted first rabbit monoclonal antibody (Bioss, Beijing, China) against $C R E B 1$ protein and $2 \mathrm{~mL} \mathrm{1:5000}$ diluted second mouse monoclonal antibody (Bioss, Beijing, China).

\section{Statistical analysis}

All statistical analyses were performed using SPSS 17.0 statistical software (SPSS 17.0, Chicago, IL, USA). A t-test was performed to examine the significant difference among treatments. $P<0.05$ represented significant difference, $P<0.01$ represented extremely significant difference.

\section{RESULTS}

\section{Expression level of miR-1468 in pituitary cells}

The pituitary cells were transfected with miR-1468 mimics and inhibitor, and qPCR was used to detect miR1468 expression. Transfection of miR-1468 mimics significantly increased miR-1468 expression level, while transfection of miR-1468 inhibitor significantly decreased miR-1468 expression level $(P<0.01)$ (Fig. 1A and $1 \mathrm{~B})$. 


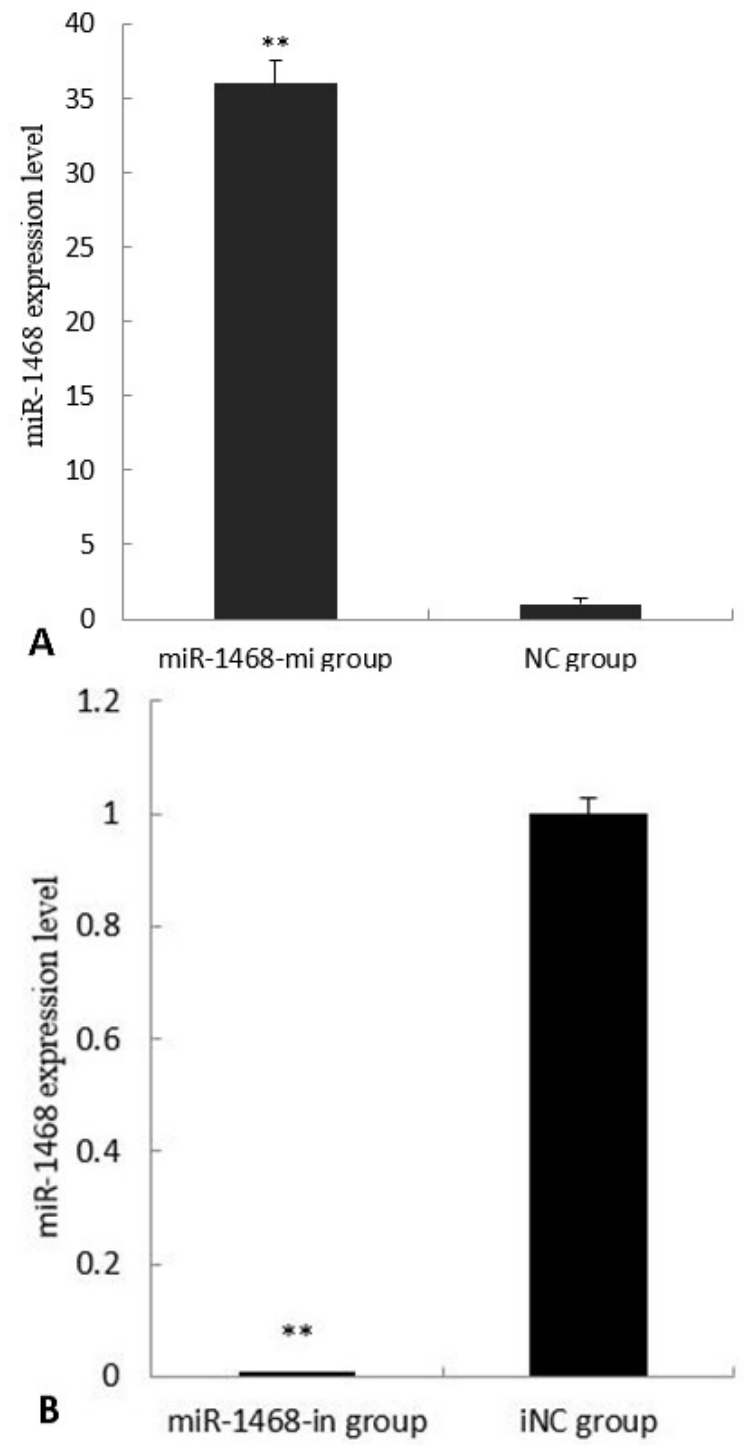

Fig. 1. Expression level of miR-1468 in pituitary cells of Yanbian yellow cattle. (A) The expression level of miR1468 in pituitary cells transfected with the mimics (miR1468-mi group) and mimics reference substance (NC group) of miR-1468. Compared with NC group, the column marked by $* *$ showed significant difference $(P<0.01)$; (B) The expression level of miR-1468 in pituitary cells transfected with the inhibitor (miR-1468-in group) and inhibitor reference substance (iNC group) of miR-1468. U6 was used as an internal reference.

\section{Effect of miR-1468 on GH mRNA transcription level}

The transcriptional level of $G H$ gene in Yanbian yellow cattle was detected by qPCR. The results showed that the $G H$ mRNA transcription level in pituitary cells of Yanbian yellow cattle in miR-1468-mi group was extremely significantly lower than that in $\mathrm{NC}$ group $(P<0.01)$ (Fig.
2A), while the $G H$ mRNA transcription level in pituitary cells of Yanbian yellow cattle in miR-1468-in group was significantly higher than that in iNC group $(P<0.05)$ (Fig. $2 \mathrm{~B})$. These results suggested that miR-1468 could regulate $G H$ transcription.
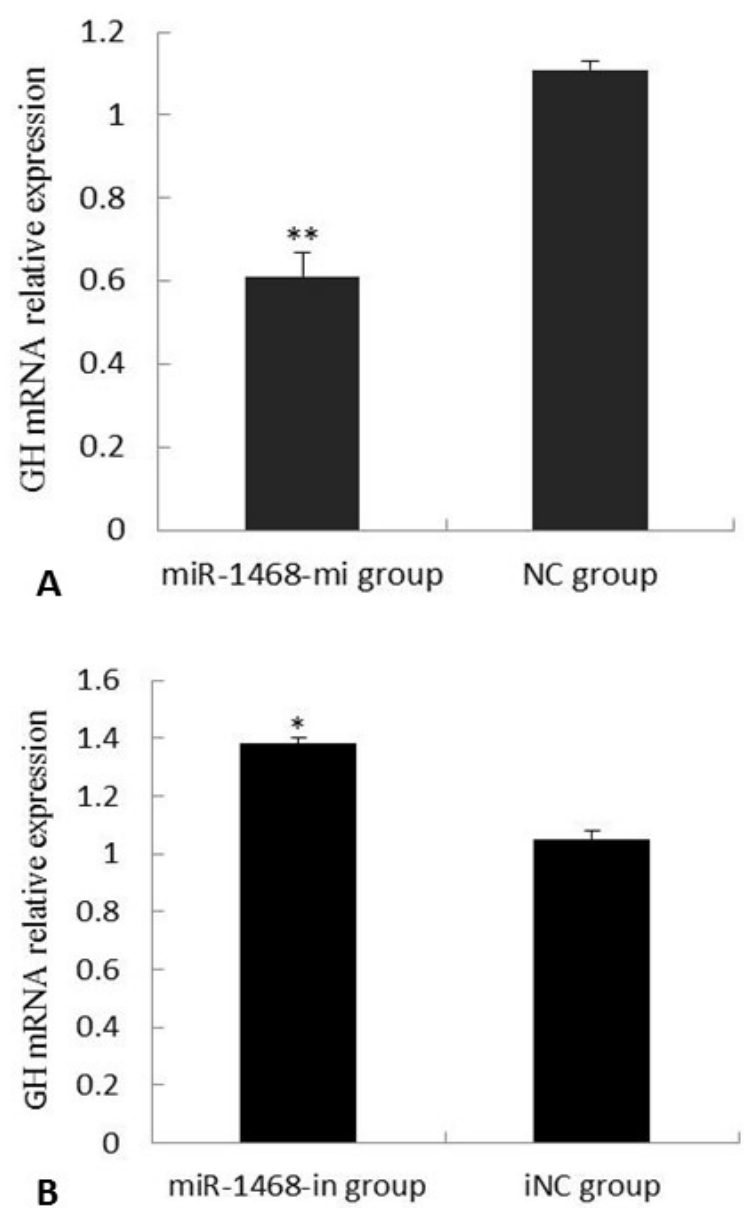

Fig. 2. Effect of miR-1468 on $G H$ mRNA transcription level in pituitary cells of Yanbian yellow cattle. (A) The relative transcription level of $G H$ mRNA in pituitary cells transfected with miR-1468 minics. Mimics (miR1468-mi group) and mimics reference substance (NC group) of miR-1468 were transfected into pituitary cells of Yanbian yellow cattle, with three replicates in each group. Compared with $\mathrm{NC}$ group, the column marking** showed extremely significant difference $(P<0.01)$; (B) The relative transcription level of $G H$ mRNA in pituitary cells transfected with miR-1468 inhibitor. Inhibitor (miR1468 -in group) and inhibitor reference substance (iNC group) of miR-1468 were transfected into pituitary cells of Yanbian yellow cattle, with three replicates in each group. Compared with iNC group, the column marking* showed significant difference $(P<0.05)$. $\beta$-actin was used as an internal reference. 
Effect of miR-1468 on GH protein expression level

In order to further verify the effect of miR-1468 on $G H, \mathrm{GH}$ protein expression level in Yanbian yellow cattle was further detected by Western blot based on the transcription results of $G H$ mRNA. The results showed that GH protein expression level in pituitary cells of Yanbian cattle in miR-1468-mi group was extremely significantly lower than that in NC group $(P<0.01)$ (Fig. $3 \mathrm{~A}$ ), while $\mathrm{GH}$ protein expression level in pituitary cells of Yanbian yellow cattle in miR-1468-in group was extremely significantly higher than that in iNC group $(P<0.01)$ (Fig. $3 \mathrm{~B})$. These results suggested that miR-1468 could regulate $\mathrm{GH}$ protein expression.
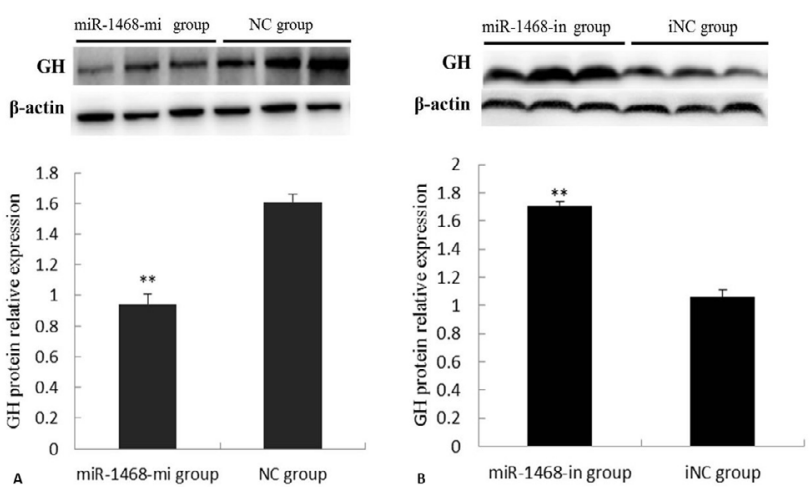

Fig. 3. Effect of miR-1468 on GH protein expression level in pituitary cells of Yanbian yellow cattle. (A) The relative expression level of GH protein in pituitary cells transfected with miR-1468 minics. Mimics (miR1468-mi group) and mimics reference substance (NC group) of miR-1468 were transfected into pituitary cells of Yanbian yellow cattle, with three replicates in each group. Compared with NC group, the column marking** showed extremely significant difference $(P<0.01)$; (B) The relative expression level of GH protein in pituitary cells transfected with miR-1468 inhibitor. Inhibitor (miR1468-in group) and inhibitor reference substance (iNC group) of miR-1468 were transfected into pituitary cells of Yanbian yellow cattle, with three replicates in each group. Compared with iNC group, the column marking** showed significant difference $(P<0.01)$. $\beta$-actin was used as an internal reference. Electrophoresis of the $G H$ and $\beta$-actin gene fragment was from two separate gels.

Prediction of the target relationship between miR-1468 and $G H$ secretion related genes

The targets can and RNA hybrids analysis software were used to analyze the target relationship between miR1468 and $G H$ secretion related genes (GHRHR, SSTR2, LEF1, POU1F1, SSTR5 and CREB1). The results showed that the target gene of miR-1468 was $C R E B 1$ (Fig. 4).

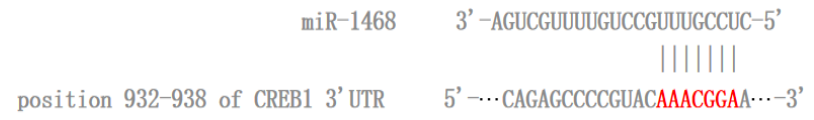

Fig. 4. Prediction of target relations for miR-1468.

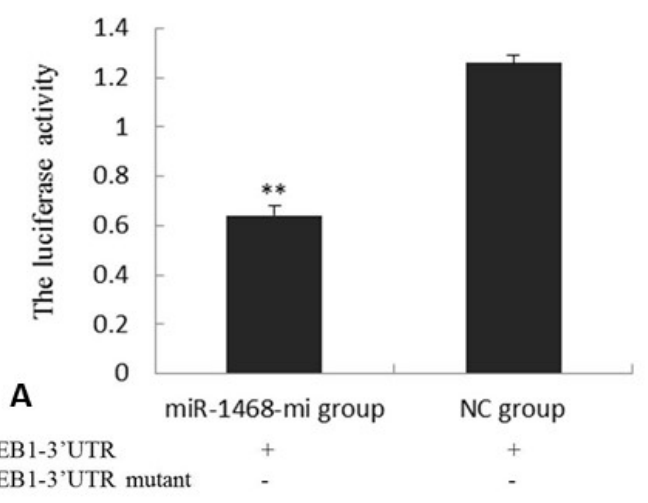

$\begin{array}{lll}\text { pirGLO-CREB1-3'UTR } & + & + \\ \text { pirGLO-CREB1-3'UTR mutant } & - & -\end{array}$

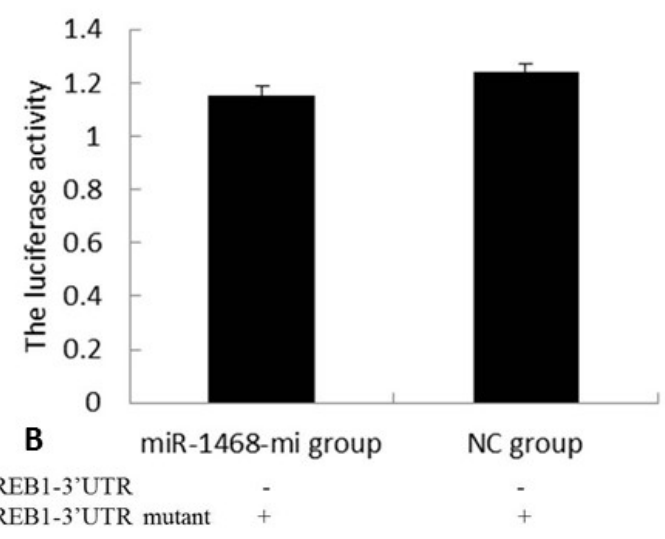

Fig. 5. Luciferase activity determination. (A) The changes of luciferase activity after PirGLO- CREB 1-3'UTR normal plasmid co-transfecting with miR-1468 mimics (miR-1468mi group) and mimics reference substance (NC group) for $48 \mathrm{~h}$. Compared with NC group, the column marking** showed extremely significant difference $(P<0.01)$; (B) The changes of luciferase activity after PirGLO-CREB13'UTR mutant plasmid plasmid co-transfecting with miR1468 mimics (miR-1468-mi group) and mimics reference substance (NC group) for $48 \mathrm{~h}$. Compared with NC group, the column without marking** or* showed no significant difference $(P>0.05)$.

Verification of the target relationship between miR-1468 and CREB 1

The change of luciferase activity was observed $48 \mathrm{~h}$ later, and the target relationship between miR-1468 and $C R E B 1$ was analyzed by the changes of luciferase activity. The results showed that the luciferase activity in pirGLO- 
CREB 1-3'UTR normal plasmid was significantly decreased by adding miR-1468 mimics (Fig. 5A) $(P<0.01)$, but no inhibitory effect on that in the pirGLO-CREB1-3'UTR deletion vector $(P>0.05)$ (Fig. 5B). It could be concluded that miR-1468 could bind and act on the 3'UTR region of $C R E B 1$, and there is a target relationship between miR1468 and $C R E B 1$.

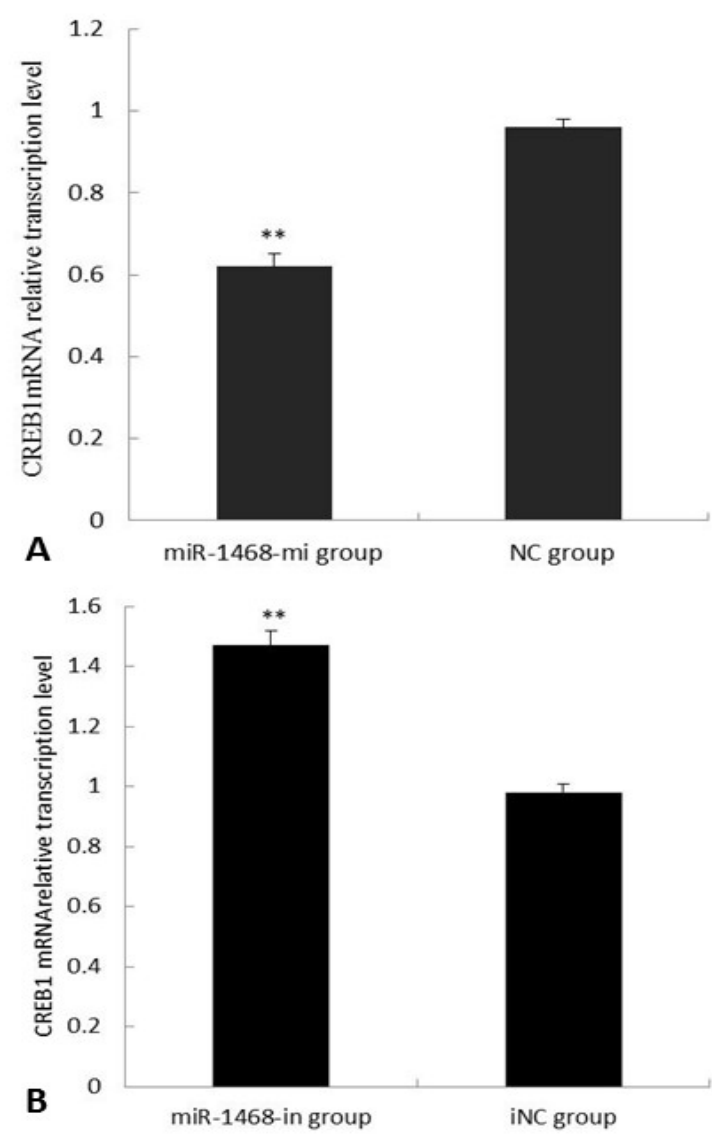

Fig. 6. Effect of miR-1468 on transcription level of $C R E B 1$ mRNA in pituitary cells of Yanbian yellow cattle. (A) The relative transcription level of CREB $1 \mathrm{mRNA}$ in pituitary cells transfected with miR-1468 minics. Mimics (miR1468-mi group) and mimics reference substance (NC group) of miR-1468 were transfected into pituitary cells of Yanbian yellow cattle, with three replicates in each group. Compared with $\mathrm{NC}$ group, the column marking** showed extremely significant difference $(P<0.01)$; (B) The relative transcription level of $C R E B 1$ mRNA in pituitary cells transfected with miR-1468 inhibitor. Inhibitor (miR1468-in group) and inhibitor reference substance (iNC group) of miR-1468 were transfected into pituitary cells of Yanbian yellow cattle, with three replicates in each group. Compared with iNC group, the column marking** showed extremely significant difference $(P<0.01)$. $\beta$-actin was used as an internal reference.
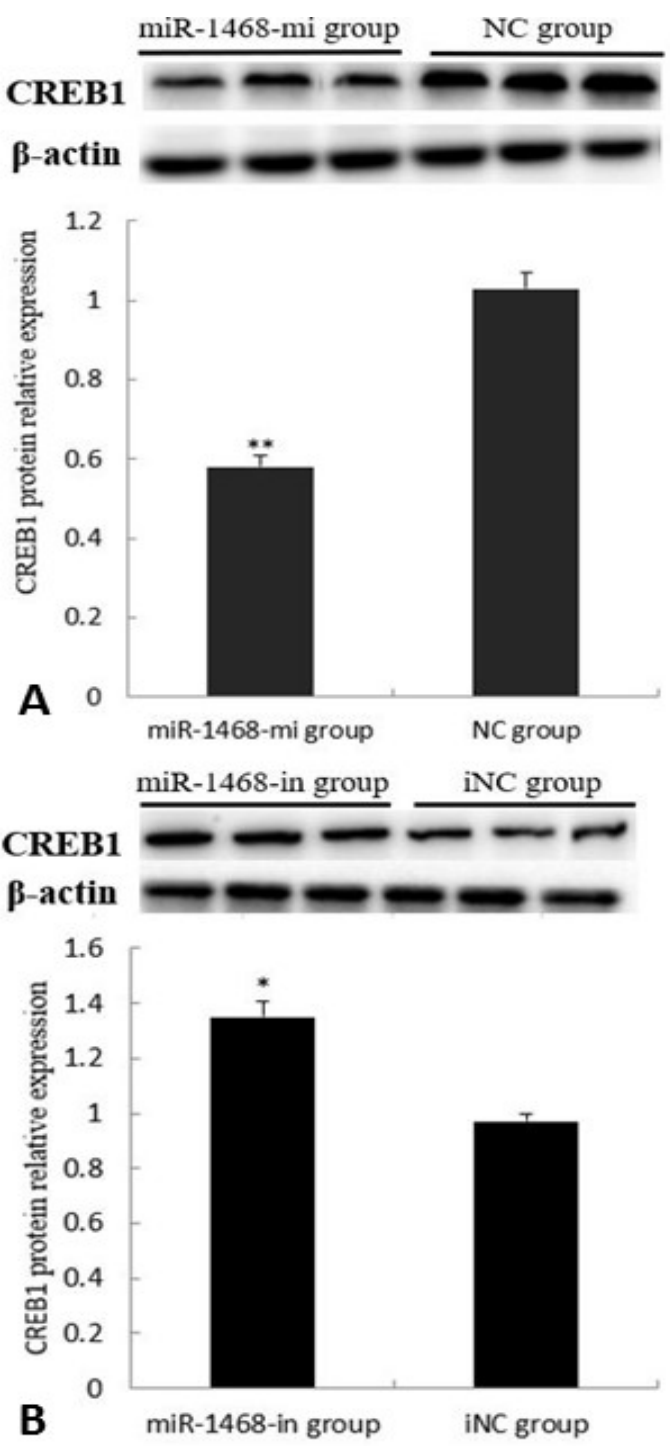

Fig. 7. Effect of miR-1468 on CREB1 protein expression level in pituitary cells of Yanbian yellow cattle. (A) The relative expression level of CREB1 protein in pituitary cells transfected with miR-1468 minics. Mimics (miR1468-mi group) and mimics reference substance (NC group) of miR-1468 were transfected into pituitary cells of Yanbian yellow cattle, with three replicates in each group. Compared with $\mathrm{NC}$ group, the column marking** showed extremely significant difference $(P<0.01)$; (B) The relative expression level of CREB1 protein in pituitary cells transfected with miR-1468 inhibitor. Inhibitor (miR1468-in group) and inhibitor reference substance (iNC group) of miR-1468 were transfected into pituitary cells of Yanbian yellow cattle, with three replicates in each group. Compared with iNC group, the column marking* showed significant difference $(P<0.05)$. $\beta$-actin was used as an internal reference. Electrophoresis of the CREB 1 and $\beta$-actin gene fragment was from two separate gels. 
Effect of miR-1468 on transcription level of CREB1 $m R N A$

In order to verify the regulatory function of miR1468 on $C R E B 1$ gene, the transcription level of CREBI mRNA was detected by qPCR. The results showed that the transcription level of CREB1 mRNA in the miR-1468-mi group was significantly lower than that in the NC group (Fig. 6A) $(P<0.01)$, while the transcription level of $C R E B 1$ mRNA in the miR-1468-in group was significantly higher than that in the iNC group (Fig. 6B) $(P<0.01)$. These results suggested that miR-1468 could regulate the transcription of CREB1.

\section{Effect of miR-1468 on CREB1 protein expression level}

In order to further verify the effect of miR-1468 on CREB1 protein expression level in pituitary of Yanbian cattle, CREB1 protein expression level was detected by Western-blot based on the transcription results of CREB1 mRNA. The results showed that the CREB1 protein expression level in the miR-1468-mi group was significantly lower than that in the NC group (Fig. 7A) $(P<0.01)$, while the CREB1 protein expression level in the miR-1468-in group was significantly higher than that in the iNC group (Fig. 7B) $(P<0.05)$. These results suggested that miR-1468 could regulate the CREB1 protein expression.

\section{DISCUSSION}

As a posttranscriptional regulatory factor, there are few studies on the regulation of miR-1468 on animal growth, especially on the relationship between miR-1468 and $G H$. Therefore, in order to determine whether miR1468 is related to $G H$, we first observed the effect of miR1468 on $G H$ mRNA transcription and protein expression at the level of pituitary cells in vitro. The results showed that miR-1468 could promote $G H$ mRNA transcription and protein expression, which indicated that there was a close relationship between miR-1468 and GH. However, previous researchers have demonstrated that the main function of miRNA is to negatively regulate the expression of target genes (Houbaviy, 2005). Therefore, we concluded that $G H$ was not directly regulated by miR-1468, and the target gene of miR-1468 needed further verification.

In order to further determine the specific regulatory mechanism of miR-1468 on $G H$, the target relationship between miR-1468 and GH secretion related regulatory genes was analyzed through biological analysis software in this study. Research data showed that GHRHR, SSTR2, LEF1, POU1F1, SSTR5 and CREB1 were the main genes related to GH synthesis and secretion (Song et al., 2007; Martari and Salvatori, 2009; Hiral et al., 2014; Li et al., 2012; Hagberg, 2010). Therefore, we observed the relationship between miR-1468 and the 3'UTR region of the above genes using targetscan and RNA hybrids software in this study. The results showed that the seed sequence of miR-1468 only had a target relationship with CREB1 gene. Some studies have shown that CREB1 protein is a transcription factor specifically expressed in animal pituitary gland, which can promote $G H$ transcription and expression and play an important regulatory role in animal growth and development (Hagberg, 2010). The results of luciferase reporter gene validation showed that the activity of luciferase in the normal pirGLO-CREB1-3'UTR vector was significantly decreased by miR-1468, but the luciferase activity in the mutant pirGLO-CREB1-3'UTR vector was not affected. These results not only indicated that there was a target relationship between miR-1468 and $C R E B 1$, but also preliminary demonstrated that miR-1468 could affect $\mathrm{GH}$ secretion by regulating the expression of CREB 1 .

After determining the relationship between miR1468 and 3'UTR of CREB1, we observed the effects of miR-1468 on CREB1 mRNA and protein of pituitary cells in vitro in this study. The pituitary cells of Yanbian cattle were transfected with miR-1468 minics and inhibitor at the cellular level, and the changes of CREB1 mRNA transcription and protein expression were detected by qPCR and Western blot. The results showed that CREB1 mRNA transcription and protein expression was significantly inhibited by the transfection of miR-1468 minics, but was significantly increased by the transfection of miR-1468 inhibitor. Therefore, it could be inferred that the regulation of miR-1468 on GH secretion was mainly achieved by targeting CREB1. The present study further revealed that the main role of miRNA was to negatively regulate the expression of target genes, which was consistent with the previous study (Houbaviy, 2005; Shi and Sun, 2016; Valencia et al., 2014).

\section{CONCLUSIONS}

These results demonstrated that miR-1468 could regulate $G H$ by targeting $C R E B 1$. The result of this study will not only provide a theoretical basis for further study the mechanism of miRNA on regulating animal growth and development, but also provide a new target for the growth and development regulation of Yanbian yellow cattle.

\section{ACKNOWLEDGEMENTS}

This work was supported by grants from National Natural Science Foundation of China (31660614) and PhD research funding of Linyi University (LYDX2018BS024). 
Statement of conflict of interest

The authors have declared no conflict of interest.

\section{REFERENCES}

Allen, C.D., Lee, S., Koob, G.F. and Rivier, C., 2011. Immediate and prolonged effects of alcohol exposure on the activity of the hypothalamicpituitary-adrenal axis in adult and adolescent rats. Brain Behav. Immun., 25: S50-S60. https://doi. org/10.1016/j.bbi.2011.01.016

Bartke, A., Dominici, F., Turyn, D., Kinney, B., Steger, R. and Kopchick, J.J., 2003. Insulin-like growth factor 1 (IGF-1) and aging: Controversies and new insights. Biogerontology, 4: 1-8. https://doi. org/10.1023/A:1022448532248

Bustin, S.A. and Jenkins, P.J., 2001. The growth hormone-insulin-like growth factor-I axis and colorectal cancer. Trends mol. Med., 7: 447-454. https://doi.org/10.1016/S1471-4914(01)02104-9

Chen, T., Xi, Q.Y., Ye, R.S., Xiao, C. and Zhang, Y.L. 2014. Exploration of microRNAs in porcine milk exosomes. BMC Genom., 15: 100-105. https://doi. org/10.1186/1471-2164-15-100

Gesing, A., Wiesenborn, D. and Do, A., 2016. A longlived mouse lacking both growth hormone and growth hormone receptor: A new animal model for aging studies. J. Gerontol., 72: 1054-1056. https:// doi.org/10.1093/gerona/glw193

Hagberg, J.M., 2010. cAMP responsive element binding protein 1 (CREB1; CREB). SciBX: Sci. Bus. eXchange, 3: 229-231. https://doi.org/10.1161/ CIRCGENETICS.110.957357

Han Y., Wei, L.R. and Sun, L.L., 2010. Effect of glycine on the development of somatic cell cloned reorganization embryo of Yanbian yellow cattle. Hubei agric. Sci., 30: 411-413.

Hiral, A., Judy, V., Alicia, H., Nury, S., Reuben, H. and Susan, T.A., 2014. GSK3 $\beta$ inhibition and LEF1 upregulation in skeletal muscle following a bout of downhill running. J. physiol. Sci., 64: 1-11. https:// doi.org/10.1007/s12576-013-0284-5

Houbaviy, H., 2005. Characterization of a highly variable eutherian microrna gene. $R N A, 11: 1245$ 1257. https://doi.org/10.1261/rna.2890305

Ji, S., Yang, R., Lu, C., Qiu, Z. and Yan, C., 2014. Differential expression of PPAR, FASN, and ACADM genes in various adipose tissues and longissimus dorsi muscle from Yanbian Yellow Cattle and Yan Yellow Cattle. Asian Austral. J. Anim. Sci., 27: 10-13. https://doi.org/10.5713/ ajas.2013.13422
King, D., Jarjoura, D., McEwen, H.A. and Askew, M.J., 2005. Growth hormone injections improve bone quality in a mouse model of osteogenesis imperfecta. J. Bone Min. Res., 20: 987-993. https:// doi.org/10.1359/JBMR.050108

Li, F.L., Chu, Q., Xu, M.P., Yao, X.H. and Shen, J.F., 2012. Expression of somatostatin receptors subtype 2 and 5 in extraocular muscle tissue of hypothyroidism animal induced by (13)1I. Label. Immunoass. clin. Med., 4: 24-25.

Lou, A.G., Yang, Y.J., Jin, T.H., Zhang, R., Cui, C.D., Yu, L.Z. and Guan, L.Z., 2019. Differential expression analysis of miRNA in blood exosomes of Yanbian Yellow Cattle and Hanyan Cattle. Shandong $J$. Anim. Sci. Vet. Med., 40: 6-9. (in Chinese)

Martari, M. and Salvatori, R., 2009. Diseases associated with growth hormone-releasing hormone receptor (GHRHR) mutations. Prog. mol. Biol. Transl. Sci., 88: 57-84. https://doi.org/10.1016/S18771173(09)88003-4

Melnik, B.C., John, S.M. and Schmitz, G., 2013. Milk is not just food but most likely a genetic transfection system activating mTORC1 signaling for postnatal growth. Nutr. J., 12: 103-107. https:// doi.org/10.1186/1475-2891-12-103

Piotrowska, K., Sluczanowska-Glabowska, S., Kucia, M., Bartke, A., Laszczynska, M. and Ratajczak, M.Z., 2017. Histological changes of testes in growth hormone transgenic mice with high plasma level of GH and insulin-like growth factor-1. Folia Histochem. Cytobiol., 53: 249-258. https://doi. org/10.5603/fhc.a2015.0024

Qi, Q., Xi, Q., Ye, R.S., Chen, T., Cheng, X., Li, C. and Zhang, Y., 2015. Alteration of the miRNA expression profile in male porcine anterior pituitary cells in response to GHRH and CST and analysis of the potential roles for miRNAs in regulating $\mathrm{GH}$. Growth Horm. IGF Res., 25: 66-74. https://doi. org/10.1016/j.ghir.2014.12.002

Shi, J. and Sun, G., 2016. Effect of pre-miRNA-1658 gene polymorphism on chicken growth and carcass traits. Asian Austral. J. Anim. Sci., 30: 40-45. https://doi.org/10.5713/ajas.16.0305

Song, C.Y., Gao, B., Teng, S.H., Wang, X.Y., Xie, F., Chen, G.H. and Mao, J.D., 2007. Polymorphisms in intron 1 of the porcine POU1F1 gene. J. appl. Genet., 48: 371-374. https://doi.org/10.1007/ BF03195234

Tian, W.N., Zhang, S.F., Xiang, L.I., Gao, Q.S., Jin, X. and Yan, C.G., 2011. Genetic polymorphism and correlation analysis with growth traits of ACTA1 Gene in Yanbian Yellow Cattle. China Anim. Husb. 
vet. Med., 38: 190-193.

Valencia, K., Luis-Ravelo, D., Bovy, N., Antón, I., Martínez-Canarias, S., Zandueta, C. and Rebmann, V., 2014. miRNA cargo within exosome-like vesicle transfer influences metastatic bone colonization. Mol. Oncol., 8: 689-703. https://doi.org/10.1016/j. molonc.2014.01.012
Vgontzas, A.N., Mastorakos, G., Bixler, E.O., Kales, A., Gold, P.W. and Chrousos, G.P., 2010. Sleep deprivation effects on the activity of the hypothalamic-pituitary-adrenal and growth axes: potential clinical implications. Clin. Endocrinol., 51: 205-215. https://doi.org/10.1046/j.13652265.1999.00763.x 